\title{
Fine-scale temperature-associated genetic structure between inshore and offshore populations of sea scallop (Placopecten magellanicus)
}

\author{
Sarah J. Lehnert $\mathbb{D}^{1} \cdot$ Claudio DiBacco ${ }^{2} \cdot$ Mallory Van Wyngaarden $\mathbb{1}^{3} \cdot$ Nicholas W. Jeffery $\mathbb{D}^{2} \cdot$ J. Ben Lowen ${ }^{2} \cdot$ \\ Emma V. A. Sylvester ${ }^{1} \cdot$ Brendan F. Wringe $\mathbb{1}^{2} \cdot$ Ryan R. E. Stanley $^{2} \cdot$ Lorraine C. Hamilton $^{4} \cdot$ Ian R. Bradbury ${ }^{1}$
}

Received: 29 September 2017 / Revised: 16 April 2018 / Accepted: 16 April 2018 / Published online: 17 May 2018

(c) The Genetics Society 2018

\begin{abstract}
In the northwest Atlantic Ocean, sea scallop (Placopecten magellanicus) has been characterized by a latitudinal genetic cline with a breakpoint between northern and southern genetic clusters occurring at $\sim 45^{\circ} \mathrm{N}$ along eastern Nova Scotia, Canada. Using 96 diagnostic single-nucleotide polymorphisms (SNPs) capable of discriminating between northern and southern clusters, we examined fine-scale genetic structure of scallops among 27 sample locations, spanning the largest geographic range evaluated in this species to date $\left(\sim 37-51^{\circ} \mathrm{N}\right)$. Here, we confirmed previous observations of northern and southern groups, but we show that the boundary between northern and southern clusters is not a discrete latitudinal break. Instead, at latitudes near the previously described boundary, we found unexpected patterns of fine-scale genetic structure occurring between inshore and offshore sites. Scallops from offshore sites, including St. Pierre Bank and the eastern Scotian Shelf, clustered with southern stocks, whereas inshore sites at similar latitudes clustered with northern stocks. Our analyses revealed significant genetic divergence across small spatial scales (i.e., 129-221 km distances), and that spatial structure over large and fine scales was strongly associated with temperature during seasonal periods of thermal minima. Clear temperature differences between inshore and offshore locations may explain the fine-scale structuring observed, such as why southern lineages of scallop occur at higher latitudes in deeper, warmer offshore waters. Our study supports growing evidence that fine-scale population structure in marine species is common, often environmentally associated, and that consideration of environmental and genomic data can significantly enhance the identification of marine diversity and management units.
\end{abstract}

Electronic supplementary material The online version of this article (https://doi.org/10.1038/s41437-018-0087-9) contains supplementary material, which is available to authorized users.

Sarah J. Lehnert

sarah.lehnert@dfo-mpo.gc.ca

1 Fisheries and Oceans Canada, Northwest Atlantic Fisheries Centre, St. John's, NL A1C 5X1, Canada

2 Fisheries and Oceans Canada, Bedford Institute of Oceanography, Dartmouth, NS B2Y 4A2, Canada

3 Department of Biology, Memorial University of Newfoundland, St. John's, NL A1C 5S7, Canada

4 Aquatic Biotechnology Laboratory, Fisheries and Oceans Canada, Bedford Institute of Oceanography, Dartmouth, NS B2Y 4A2, Canada

\section{Introduction}

Many marine species are characterized by a planktonic larval stage, and, given few conspicuous barriers to dispersal in the ocean, the potential for connectivity among populations across broad spatial scales may be significant (Cowen and Sponaugle, 2009; Hellberg, 2009). While patterns of weak genetic structure across large geographic ranges are found in some marine species (Gaither et al. 2011; Simpson et al. 2014; Yahagi et al. 2017), these cases may represent exceptions rather than the rule (Hauser and Carvalho 2008). Advances in marine genetics and genomics are increasingly revealing that, despite high dispersal potential, fine-scale genetic structure does occur within many marine species (Knutsen et al. 2007; Selkoe et al. 2008; Benestan et al. 2015; Gagnaire et al. 2015).

Fine-scale genetic structure in marine systems has been attributed to a combination of oceanographic and biological processes often influencing larval dispersal (Stanley et al. 
2012; Treml et al. 2015), such as complex oceanographic features and larval behavior (Taylor and Hellberg, 2003; Jones et al. 2005; Knutsen et al. 2007; Bradbury et al. 2008; Teske et al. 2015). Oceanographic currents can move larvae long distances (Simpson et al. 2014), or complex oceanographic circulation patterns can retain larvae producing finescale genetic differentiation (i.e., Panulirus argus; Truelove et al. 2016). Similarly, larval behavior (i.e., vertical migration) can restrict dispersal and gene flow, thus leading to highly structured populations (Bradbury et al. 2008). However, in addition to processes that influence dispersal, recent evidence also suggests natural selection and/or intrinsic barriers to gene flow may constrain connectivity in the ocean (Clarke et al. 2010; Bradbury et al. 2013; Momigliano et al. 2017; Van Wyngaarden et al. 2017).

Adaptation to the local environment can result in genetic divergence over small spatial scales, where heterogeneous environments drive genetic differences between populations (Jørgensen et al. 2005; Bradbury et al. 2010; Milano et al. 2014; Silva et al. 2014; Benestan et al. 2016). For example, in Atlantic silverside (Menidia menidia), latitudinal genetic variation exists for several traits (e.g., temperaturedependent sex determination) despite significant dispersal among distant sites (Schultz and Conover, 1997; Schultz et al. 1998; Clarke et al. 2010; Duffy et al. 2015). Similarly, climate-associated clinal genetic variation has been observed in several species in the northwest Atlantic Ocean (Stanley et al. 2018) over fine spatial scales. Growing evidence of significant population structure counters widely held perceptions of panmixia in the marine environment, and represents a paradigm shift in marine ecology that has significant consequences for the management and conservation of marine species (Hauser and Carvalho, 2008; Reiss et al. 2009).

Sea scallop (Placopecten magellanicus Gmelin, 1791; Pectinidae: Bivalvia) is one of eastern North America's most important commercial fisheries (Naidu and Robert, 2006), ranking third in the United States and fourth in Canada in terms of landed values ( $\$ 440$ million (USD) and \$184 million (CAD); NOAA, 2016; DFO, 2016a). Sea scallops are native to the northwest Atlantic Ocean, and the species range extends from northern Newfoundland (NL), Canada, to Cape Hatteras in North Carolina, US (Posgay 1957). Generally, sea scallops are found on the continental shelf at depths ranging from 10 to $100 \mathrm{~m}$ where they form high-density benthic aggregations known as 'beds' (Naidu and Robert 2006). Although sea scallop adults are primarily sedentary with limited dispersive capacity (Melvin et al. 1985), they are highly fecund broadcast spawners that produce planktonic larvae that can remain in the water column for up to 40 days (Culliney 1974; Naidu and Robert 2006). Given their planktonic larval duration, it is likely that scallop larvae have extensive dispersal ability resulting in connectivity between stocks (Tian et al. 2009; Davies et al. 2014).

Despite relatively high dispersal potential, the genetic structure of sea scallops is characterized by two broadly defined genetic clusters (northern and southern clusters) with a genetic breakpoint occurring along the coast of eastern Nova Scotia (NS; Van Wyngaarden et al. 2017) potentially associated with environmental variation (Van Wyngaarden et al. 2018). Across the range, sea scallops occupy a variety of habitats encompassing gradients of depth, substrate, temperature, and ocean chemistry (Townsend et al. 2004; Naidu and Robert 2006; Van Wyngaarden et al. 2018). Broad-scale genetic-environment associations have been examined using a suite of environmental variables (e.g., temperature, salinity, seawater density, chlorophyll A, and inorganic nutrient concentrations; Van Wyngaarden et al. 2018). Colder temperatures (winter and annual minima) and to a lesser extent salinity were strongly associated with genetic variation, potentially implicating post-settlement selection as a driver of broad-scale structure (Van Wyngaarden et al. 2018). In addition to clinal structuring, some evidence exists that fine-scale genetic structure may be present within some regions such as the Gulf of Maine and Georges Bank (Kenchington et al. 2006; Owen and Rawson 2013).

In our study, the main objective is to explore the presence and fine-scale distribution of northern and southern genetic clusters of sea scallop and examine possible drivers of finescale structure. We build on previous genetic and genomic studies (Kenchington et al. 2006; Owen and Rawson, 2013; Van Wyngaarden et al. 2017, 2018) through increased sampling spanning the largest geographic range to date. We genotyped adult scallops from across the range utilizing a small panel of diagnostic (high $F_{\mathrm{ST}}$ with low linkage disequilibrium) single-nucleotide polymorphisms (SNPs) capable of discriminating between the northern and southern genetic clusters. In addition, given the potential role of cold temperatures on post-settlement survival (Van Wyngaarden et al. 2018), we genotyped pre- and post-winter juvenile scallops from a subset of locations to evaluate the role of selection in shaping genetic structure. Further, as previous evidence suggests that fine-scale genetic structure exists in parts of the sea scallop range (Kenchington et al. 2006; Owen and Rawson 2013), genotype data were analyzed in combination with salinity and temperature data to evaluate how environmental conditions potentially mediate fine-scale genetic structure, and thus provide valuable insight into the mechanisms driving genetic structure in an ocean characterized by few obvious physical barriers to gene flow. A more informed evaluation of genetic population structure in the economically significant sea scallop is necessary to ensure integration between management action and the biological units of interest. 
Table 1 Sea scallop (Placopecten magellanicus) sampling site locations and codes with the number of individuals sampled for each life stage and sampling year

\begin{tabular}{|c|c|c|c|c|c|c|}
\hline Code & Location & $N$ & Life stage & Year & Lat $\left({ }^{\circ} \mathrm{N}\right)$ & Long $\left({ }^{\circ} \mathrm{W}\right)$ \\
\hline $\mathrm{MDA}^{\mathrm{ab}}$ & Mid-Atlantic & 41 & Adult & 2012 & 37.54 & -74.70 \\
\hline LIS $^{b}$ & Long Island (formerly MDA Group 1) & 36 & Adult & 2013 & 40.84 & -71.89 \\
\hline $\mathrm{NGB}^{\mathrm{b}}$ & NOAA Georges Bank (formerly MDA Group 2) & 39 & Adult & 2013 & 41.05 & -69.02 \\
\hline $\mathrm{GMO}^{\mathrm{a}}$ & Gulf of Maine—offshore & 42 & Adult & 2012 & 42.45 & -70.39 \\
\hline $\mathrm{GEO}^{\mathrm{a}}$ & Georges Bank & 38 & Adult & 2012 & 41.61 & -66.36 \\
\hline $\mathrm{GMI}^{\mathrm{a}}$ & Gulf of Maine-inshore & 40 & Adult & 2012 & 44.52 & -67.03 \\
\hline \multirow[t]{2}{*}{$\mathrm{PSB}^{\mathrm{a}}$} & \multirow[t]{2}{*}{ Passamaquoddy Bay, NB } & 32 & Adult & 2012 & 45.06 & -67.02 \\
\hline & & 47 & Spat & 2015 & 45.08 & -67.08 \\
\hline $\mathrm{BFU}$ & Bay of Fundy-upper & 40 & Adult & 2015 & 45.50 & -64.90 \\
\hline BFS & Bay of Fundy-Scots Bay/Spencer's Island & 40 & Adult & 2015 & 45.35 & -64.70 \\
\hline $\mathrm{BOF}^{\mathrm{a}}$ & Bay of Fundy & 40 & Adult & 2012 & 44.68 & -66.07 \\
\hline BFA & $\begin{array}{l}\text { Bay of Fundy-St. Andrews/South of Grand } \\
\text { Manan }\end{array}$ & 40 & Adult & 2015 & 44.62 & -66.65 \\
\hline SSG & Offshore-Scotian Shelf-German & 40 & Adult & 2012 & 43.30 & -66.50 \\
\hline $\mathrm{SSB}^{\mathrm{a}}$ & Offshore-Scotian Shelf-Browns & 42 & Adult & 2012 & 42.84 & -66.14 \\
\hline SFA & Scallop Fishing Area (SFA) 29 & 32 & Adult & 2012 & 43.32 & -65.52 \\
\hline \multirow[t]{3}{*}{$\mathrm{CHE}$} & \multirow[t]{3}{*}{ Chester, NS } & 21 & Adult & 2015 & 44.53 & -64.24 \\
\hline & & 49 & Spat & 2015 & 44.40 & -64.29 \\
\hline & & 49 & Spat & 2016 & 44.40 & -64.30 \\
\hline SSW & Offshore-Scotian Shelf_-Sable/Western & 40 & Adult & 2012 & 43.69 & -61.84 \\
\hline $\mathrm{SSM}^{\mathrm{a}}$ & Offshore-Scotian Shelf-Middle & 36 & Adult & 2012 & 44.52 & -60.64 \\
\hline SSQ & Offshore-Scotian Shelf-Banquereau & 37 & Adult & 2012 & 44.43 & -59.57 \\
\hline \multirow[t]{2}{*}{ CDB } & \multirow[t]{2}{*}{ Chedabucto Bay, NS } & 48 & Spat & 2015 & 45.50 & -61.22 \\
\hline & & 50 & Spat & 2016 & 45.50 & -61.22 \\
\hline \multirow[t]{2}{*}{$\mathrm{SAB}$} & \multirow[t]{2}{*}{ Cabot Strait, St. Anne's Bay, Cape Breton } & 48 & Spat & 2015 & 46.34 & -60.47 \\
\hline & & 50 & Spat & 2016 & 46.34 & -60.46 \\
\hline \multirow[t]{2}{*}{ AIG } & \multirow[t]{2}{*}{ Arisaig, NS } & 8 & Spat & 2015 & 45.80 & -62.10 \\
\hline & & 50 & Spat & 2016 & 45.80 & -62.11 \\
\hline $\mathrm{MGD}^{\mathrm{a}}$ & Magdalen Islands & 40 & Adult & 2012 & 47.11 & -62.02 \\
\hline $\mathrm{NTS}^{\mathrm{a}}$ & Northumberland Straight & 40 & Adult & 2012 & 47.13 & -65.12 \\
\hline STB & St. Pierre Bank & 40 & Adult & 2015 & 46.46 & -56.90 \\
\hline $\mathrm{LTB}^{\mathrm{a}}$ & Little Bay, NL & 41 & Adult & 2012 & 47.16 & -55.11 \\
\hline SUN $^{\mathrm{a}}$ & Sunnyside, Trinity Bay, NL & 34 & Adult & 2013 & 47.81 & -53.86 \\
\hline CRQ & Croque, NL & 38 & Adult & 2015 & 51.06 & -55.82 \\
\hline
\end{tabular}

Sites are ordered from south to north

${ }^{a}$ Indicates that some individuals $(n=12-22 /$ site) were previously genotyped by Van Wyngaarden et al. 2017

${ }^{\mathrm{b}}$ Several neighboring sites sampled as one location

\section{Materials and Methods}

\section{Sample collection}

Muscle tissue samples from sea scallop adults were collected from 24 sites across eastern North America from 2012 to 2015 (Table 1 and Fig. 1). In addition to adult samples, scallop spat (young-of-the-year) were collected from two of the adult locations (Passamaquoddy Bay, New Brunswick (NB) and Chester, NS) as well as three additional locations in NS (Arisaig, Chedabucto and St.
Anne's Bay; see Table 1 and Fig. 1). To examine the potential role of post-settlement selection in shaping genetic structure in sea scallop (Van Wyngaarden et al. 2018), four of the five spat-sampling locations in our study, were sampled both pre- (November/December 2015) and post-winter (May 2016; see Table 1). Overall, the 24 adult sites plus an additional three locations for spat sampling equated to a total of 27 different sites, and all tissue samples from these sites were preserved in AllProtect (Qiagen, Toronto, ON, Canada) or $80 \%$ ethanol. 


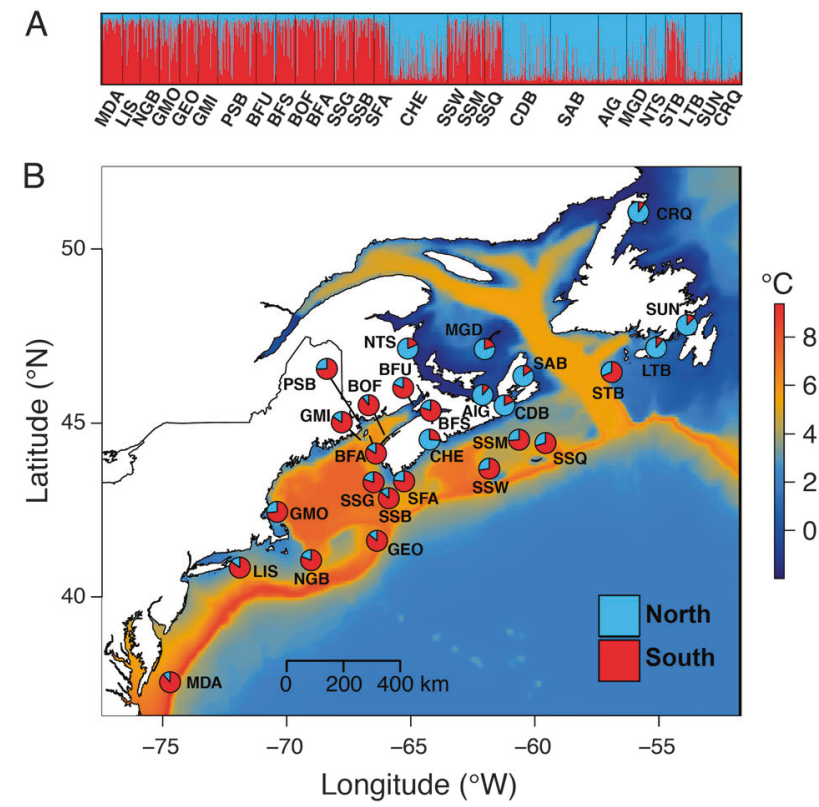

Fig. 1 Results of Bayesian clustering analysis for sea scallop (Placopecten magellanicus) sampling locations using 96 collectively diagnostic loci. a Individual assignment of scallops to two genetic clusters (north (blue) and south (red)) where each individual is represented by a vertical bar indicating the proportion of membership to each cluster. b Map of sampling locations with the proportion of membership assigned to two genetic clusters. The optimal number of clusters (K) was determined based on the delta K statistic of Evanno et al. 2005. Sites are overlaid on winter bottom temperatures averaged from 2011 to 2015, where color scale indicates temperature in degrees Celsius. Site abbreviations are listed in Table 1

\section{DNA extraction and SNP genotyping}

DNA was isolated from the tissue samples using DNeasy 96 Blood and Tissue kit (Qiagen, Toronto, ON Canada) following the protocol from the manufacturer, without optional RNase A (Qiagen) treatment. All DNA samples were quantified following the same protocol as described in Van Wyngaarden et al. (2017) using Quant-iT PicoGreen dsDNA Assay Kit (Thermo Fisher Scientific, Waltham, MA, USA) and the FLUOStar OPTIMA fluorescence plate reader (BMG Labtech, Ortenberg, Germany). A subset of scallops $(n=238)$ from 12 sites in our study (see Table 1 ) were previously genotyped at 7163 SNPs using restrictionsite-associated DNA sequencing (RAD-seq; see Van Wyngaarden et al. 2017). Of the 7163 SNPs, a panel of diagnostic SNPs, comprising those with the highest $F_{\mathrm{ST}}$ that also showed low linkage disequilibrium, was created. During panel construction, candidate SNP Type assays (Fluidigm, San Francisco, CA, USA) were tested on a set of samples, which included samples that were used to generate the RAD-seq libraries as these would have known genotypes at the target loci (Van Wyngaarden et al. 2017). Loci were selected for inclusion in the final SNP panel based on the SNP Type assay results including (1) the cluster pattern being easy to interpret, (2) the generation of correct genotypes for known samples and positive controls (see below), (3) reproducible genotypes across multiple chip runs, and (4) the ranking of the target SNP in the prioritized list. The final panel consisted of 96 SNPs (see Table S1) and 20\% of these SNPs were previously identified as environmentally associated outliers using one or more detection methods with a data set of 90 environmental variables (Van Wyngaarden et al. 2018). gBlocks (Integrated DNA Technologies, Coralville, IA, USA) were designed and synthesized for use as positive controls (Richards-Hrdlicka 2014).

A total of 1104 scallops from 27 locations (including individuals from 15 new sites and additional individuals from the same 12 sites from Van Wyngaarden et al. 2017) were genotyped using the SNP Type assays (Fluidigm) as per the manufacturer's protocols with the STA (specific target amplification) step, using 96.96 genotyping integrated fluidic circuits and read on an EP1 (Fluidigm) and analyzed using SNP Genotyping Analysis software (Fluidigm). DNA samples had all been extracted previously, and each 96-well plate set-up included 10 samples that were repeated on the plate (redundants) to detect processing errors (row or plate reversal) and ensure consistent clustering interpretation. Samples below the genotype quality threshold ( $>9$ failed loci) were dropped from the data set (34 samples in total; 3\%). A subset of samples (8.6\%) was reanalyzed, including re-extraction of DNA from the original tissue if available, in order to calculate the genotyping error rate. The genotype error rate was calculated based on Pompanon et al. 2005 to be 0.005 . This is slightly higher than other reported studies (0-0.002; Larson et al. 2013; Petrou et al. 2013; Hess et al. 2015). After quality-checking and prior to genetic analyses, our Fluidigm genotype data $(n=1070)$ were combined with publicly available data $(n$ =238) from Van Wyngaarden et al. (2017) using genepopedit (Stanley et al. 2017).

\section{Population genetic structure}

Pairwise genetic divergence $\left(F_{\mathrm{ST}}\right)$ was calculated using ARLEQUIN v3.5 (Excoffier and Lischer 2010) for all 27 sites and all samples. Using all pairwise $F_{\mathrm{ST}}$ values between sampling sites, a heatmap was created using the $\mathrm{R}$ package gplots (Warnes et al. 2016). Next, population structure was examined using non-metric multidimensional scaling (nMDS) analysis based on population allele frequencies in vegan (Oksanen et al. 2017) and Bayesian clustering using the program STRUCTURE v2.3.4 (Pritchard et al. 2000). All STRUCTURE runs were implemented through the $\mathrm{R}$ package ParallelStructure (Besnier and Glover 2013) with $\mathrm{K}$ values tested ranging from 1 to 27 (i.e., total number of sites). For each value of $\mathrm{K}$, three independent Markov Chain Monte Carlo (MCMC) 
runs were performed using 100,000 burn-in and 500,000 iterations. The delta $\mathrm{K}$ statistic described by Evanno et al. 2005 was used to determine the best $\mathrm{K}$ for the data set using STRUCTURE HARVESTER (Earl and vonHoldt 2012). Genetic clusters were visualized using CLUMPAK (Kopelman et al. 2015), and admixture coefficients (Q value) from STRUCTURE were used in subsequent analyses.

Next, spatial genetic relationships were further explored using spatial principal component analysis (SPCA; Jombart et al. 2008), which accounts for individual genetic variability while controlling for spatial autocorrelation (Jombart et al. 2008). SPCA was run in adegenet (Jombart 2008) with significance tests for global and local structure patterns based on 1000 permutations. Cartesian coordinates of sites were used to build a connection network using Delaunay triangulation (Upton and Fingleton 1985). Cartesian coordinates were determined in R software by reprojecting site coordinates in Cartesian space while accounting for land barriers using pairwise least-cost distances among sites calculated from NOAA bathymetry data in marmap (Pante and Simon-Bouhet 2013) and using nMDS analysis in vegan (Oksanen et al. 2017). SPCA PC axis 1 lagged scores were used to visualize differences among sites and across latitude, as these scores are generally used to better observe global structure (Jombart et al. 2008).

\section{Genetic variation across life stage: examining the role of post-settlement selection}

After examining the presence of genetic structure across the range, we next examined temporal genetic differences between samples collected from the same location using ARLEQUIN v3.5 (Excoffier and Lischer 2010), where pairwise genetic divergence $\left(F_{\mathrm{ST}}\right)$ was calculated between pre- and post-winter spat samples (four sites). Alpha level was adjusted to account for multiple comparisons (alpha $=$ $0.05 / 4=0.0125$ ). The same analyses were conducted to compare differences between adults and spat samples from the same location (two sites) to further examine the role of post-settlement selection on genetic structure. The genetic distances among life stages and site locations were also compared using a neighbor-joining tree based on CavalliSforza and Edwards 1967 chord distances calculated in POPULATIONS v1.2.33 (Langella 2012) with 1000 bootstrap replicates. FigTree v1.4 (Rambaut 2012) was used to visualize the relationships among samples.

\section{Environmental factors driving population structure}

We selected averaged annual maximum and minimum, and seasonally averaged temperature and salinity from the sea surface and bottom for all scallop sites between 2011 and 2015. All 24 environmental measures were assembled at spatial resolutions interpretable to $1 / 12^{\circ}$ (or $\sim 5 \mathrm{~km}^{2}$ ) from a numerical model (NEMO) of the northwest Atlantic Ocean (Brickman et al. 2016). All data were converted to four seasonal climatological data (2011-2015) layers, of 3 months each, effectively corresponding with winter (January-March), spring (April-June), summer (July-September), and fall (October-December). Annual minimum and maximum temperature and salinity data layers were also estimated from the modeled temperature and salinity data. All resultant data layers covering the known distribution of sea scallop were converted to ASCII grid with WGS84 global stereographic projection and a uniform land mask applied. Values for each of these environmental variables, corresponding with each georeferenced sample location, were subsequently extracted from the gridded temperature and salinity data layers using the extract by points tool in ArcMap for subsequent analyses.

To identify environmental variables associated with genetic variation, we used two different approaches: redundancy analysis (RDA) and random forest (RF) regressions. RDAs were performed using the $\mathrm{R}$ package vegan (Oksanen et al. 2017) where all 24 environmental variables (standardized) were used as constraining variables to explain allele frequencies across the 96 loci. First, the ordistep function, a stepwise permutational ordination method, was implemented in both directions (forward and backward) with 1000 permutations to select environmental variables that best explained the genetic variance. ANOVAs with 1000 permutations were used to evaluate the global significance of the RDA and marginal ANOVAs (1000 permutations) were used to evaluate the significance of each selected environmental variable. To partition the genetic variance explained by environment and space separately, we used partial RDA (pRDA) conditioned on geography (Cartesian coordinates) and pRDA conditioned on environment (selected variables) separately.

Multiple RF regressions (Breiman 2001) were run using the $\mathrm{R}$ package randomForest (Liaw and Wiener 2002) where allele frequencies for the 96 SNPs were used as individual response vectors and our 24 environmental variables (standardized) were used as the set of predictor variables. In the regressions, the number of parameters sampled for each node split (mtry) was selected using the tuneRF function in randomForest (Liaw and Wiener 2002). All other parameters were set to default with 10,000 trees for each run. To determine the relative importance of each environmental variable, the mean decrease in accuracy was averaged for each variable across runs and loci. Site-specific mean residual square error was also calculated across runs and loci. 

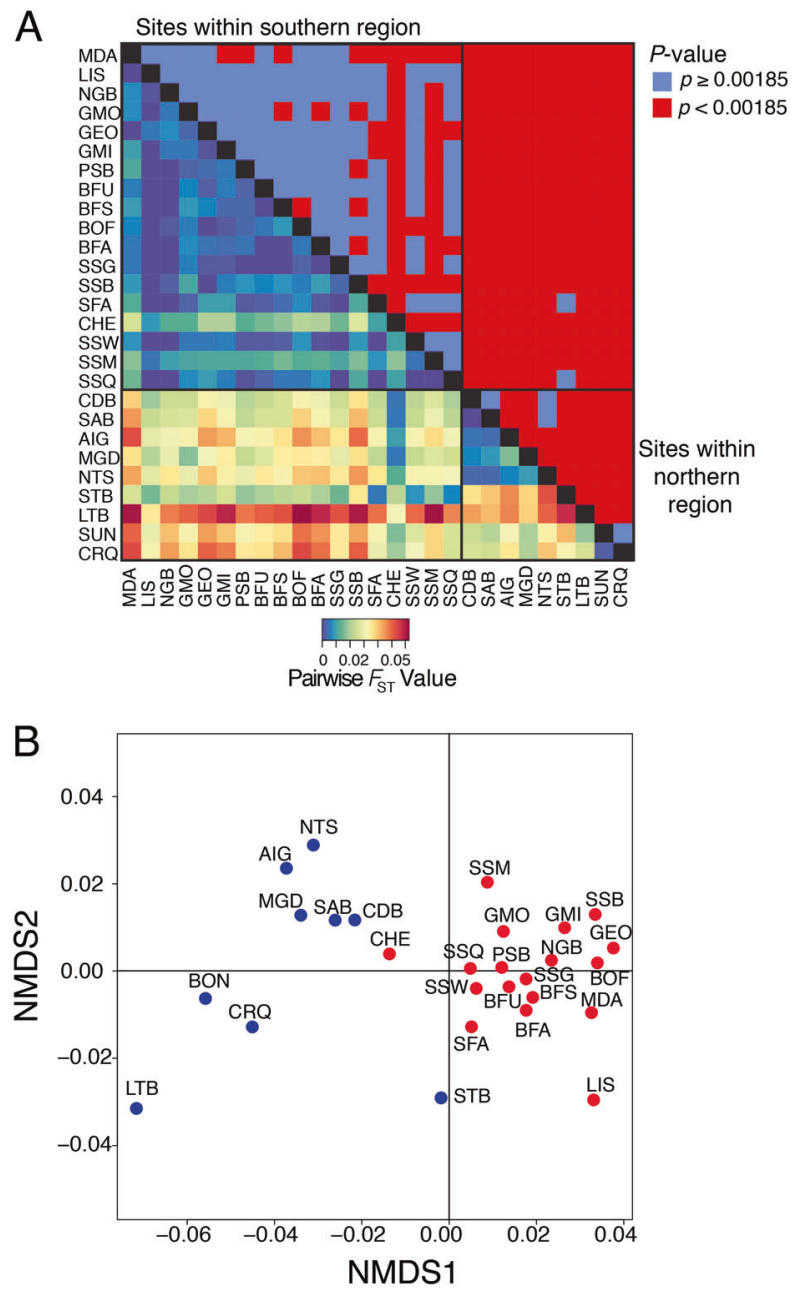

Fig. 2 a Heatmap showing pairwise genetic divergence $\left(F_{\mathrm{ST}}\right)$ below diagonal with corresponding significance ( $p$ values) above diagonal between all sea scallop (Placopecten magellanicus) sites ordered from south to north. Below the diagonal comparisons with greater divergence (high $F_{\mathrm{ST}}$ ) are indicated in red, whereas more similar comparisons (low $F_{\mathrm{ST}}$ ) are indicated in blue. Correspondingly above the diagonal, significant comparisons are indicated by red and nonsignificant $(p \geq 0.00185)$ comparisons are indicated by blue. b Nonmetric multidimensional scaling (nMDS) analysis plot of sea scallop sampling sites based on allele frequencies at 96 diagnostic loci performed using vegan (Oksanen et al. 2017). Colors of site correspond to their location being north (blue) or south (red) of the previously described genetic breakpoint. Stress for nMDS projection was relatively low (0.12)

\section{Results}

\section{Population genetic structure}

The heatmap of pairwise $F_{\mathrm{ST}}$ values revealed regions where genetic divergence was generally lower among sites across large distances as well as areas where genetic divergence was high between nearby sites (Fig. 2a). Sites within the southern region (south of $45^{\circ} \mathrm{N}$ in NS) generally showed lower genetic divergence with each other compared to other sites, where only 51 of the 153 pairwise comparisons were significant ( $p$ values $<0.002$ ). In addition, $F_{\mathrm{ST}}$ was generally lower (but often significant) among sites in northern NS and the Gulf of St. Lawrence (Fig. 2a and Table S2). Sites in Newfoundland (NL) were significantly genetically divergent from each other (with the exception of Sunnyside, Trinity Bay (SUN) and Croque (CRQ); Fig. 2a and Table S2).

Bayesian clustering analysis revealed two genetic clusters (north and south) based on the delta $\mathrm{K}$ statistic of Evanno et al. 2005 (Fig. 1a,b). STRUCTURE showed that sites south of $45^{\circ} \mathrm{N}$ (along eastern NS) clustered together, with the exception of Chester, NS (CHE), which clustered with the northern sites. Sites north of $45^{\circ} \mathrm{N}$ were all one genetic cluster with the exception of St. Pierre Bank (STB), which clustered with the southern genetic group. Relationships were consistent with nMDS analyses (Fig. 2b).

Similar spatial genetic patterns were found when evaluated using SPCA (Fig. 3a). Site locations were controlled for in the SPCA using Cartesian distances between sites and these distances closely aligned with geographic distances between sites $\left(R_{\mathrm{Adj}}^{2}=0.98, p<0.001\right)$ with a relatively low stress for nMDS projection (0.035). SPCA revealed strong global structure $(p<0.001)$ corresponding to genetic differences between the northern and southern regions (Fig. 3a), and a clinal pattern was observed across latitude (Fig. $3 b)$. However, SPCA also revealed significant local structure $(p=0.001)$ indicating fine-scale genetic structure between nearby sites (Fig. 3a). STB again showed a more southern signature (i.e., lower SPCA axis 1 lagged score) differing from the nearby LTB site (Fig. 3a). In addition, sites located in close proximity spatially (offshore and inshore sites in NS) showed different genetic signatures where inshore CDB differed from nearby offshore eastern Scotian Shelf sites (SSM, SSQ, and SSW), and similarly inshore CHE differed from these sites as well as nearby sites including SFA, SSB, and SSG (Fig. 3a).

\section{Genetic variation across life stage: examining the role of post-settlement selection}

After confirming the presence of genetic structure across the range, we next examine the possible role of post-settlement selection in shaping this genetic structure. We found no significant genetic divergence between pre- and post-winter spat samples (Table 2). When comparing spat and adults collected from the same sampling location, we found no significant genetic divergence between life stages in CHE, whereas life stages were significantly divergent in Passamaquoddy Bay, NB (PSB; $F_{\mathrm{ST}}=0.009, p<0.001$; see Table S3). The limited differences between temporal samples were further confirmed using a neighbor-joining tree, as samples from the same location generally grouped close 


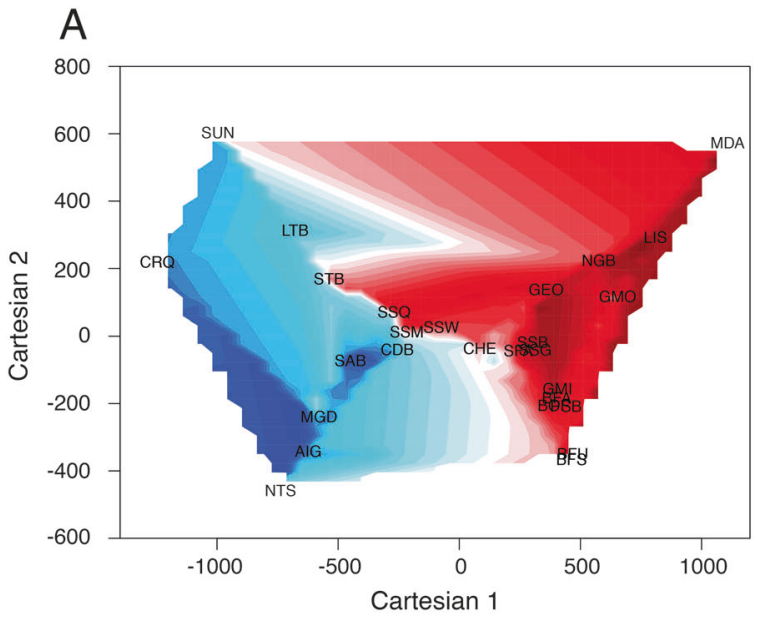

Fig. 3 a Sea scallop (Placopecten magellanicus) sampling sites plotted based on their relative spatial position based on Cartesian coordinates. Sites are overlaid on colors corresponding to their relative genetic grouping based on axis 1 lagged scores of the spatial principal

Table 2 Pairwise genetic divergence $\left(F_{\mathrm{ST}}\right)$ and significance ( $p$ value) between pre- and post-winter sea scallop (Placopecten magellanicus) spat collected from the same sampling location

\begin{tabular}{lll}
\hline Pre- and post-winter spat & Pairwise $F_{\mathrm{ST}}$ & $p$ value \\
\hline AIG & 0.00741 & 0.0820 \\
CDB & 0.00340 & 0.0262 \\
CHE & 0.00198 & 0.1188 \\
SAB & 0.00119 & 0.2126 \\
\hline
\end{tabular}

No sites showed a significant difference between pre- and post-winter spat at an adjusted alpha level of $0.0125(0.05 / 4)$

together, including both life stages from PSB (see Figure S1).

\section{Environmental factors driving population structure}

RDA identified nine environmental variables that explained genetic variation (Fig. 4a), and six of these variables were significant ( $p$ values $<0.05$ ). The RDA was globally significant $(F=3.098 ; p=0.001)$ with the first and second RDA axes explaining $16.5 \%$ and $6.7 \%$ of the genetic variation, respectively. Cold temperatures, including winter bottom temperature (BT; $F=2.24 ; p=0.035$ ), minimum sea surface temperature (SST; $F=2.38 ; p=0.021)$, and winter SST $(F=3.30 ; p=0.002)$, were significant and separated populations along the first RDA axis. Salinity variables were also significant, including minimum sea surface salinity (SSS; $F=2.52 ; p=0.020)$, spring SSS $(F$ $=2.38 ; p=0.018)$, and fall bottom salinity (BS; $F=2.50$; $p=0.016$ ), and these variables generally separated inshore sites in NS and sites in the Gulf of St. Lawrence from other regions (Fig. 4a). When geography was accounted for in the pRDA, the same six environmental variables were
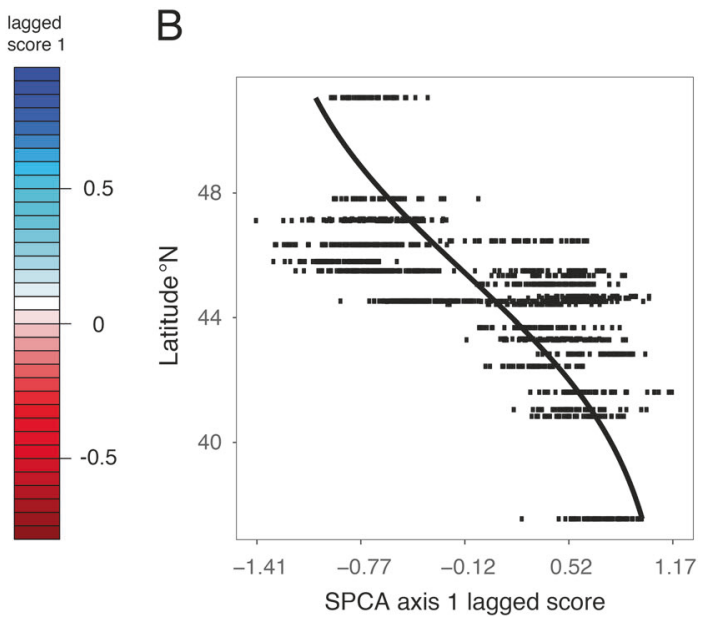

component analysis (SPCA), where red represents more southern genotypes and blue represents more northern genotypes. b Standardized SPCA axis 1 lagged scores for all sea scallops plotted against latitude for the sampling site demonstrating a latitudinal genetic cline

significant ( $p$ values $<0.05$ ). Environment and geography explained $58.2 \%$ and $8.9 \%$ of the genetic variation, respectively.

Consistent with the RDA, random forest (RF) regressions generally identified colder temperatures as important, where minimum BT, winter BT, minimum SST, as well as spring SST had the highest values for mean decrease in accuracy (Fig. 4b). The majority of other SST measures also showed high mean decrease in accuracy, whereas salinity measures were generally less important, particularly SSS measures (Fig. 4b). Sites near the extremes of the geographic range showed higher mean square errors (Fig. 4c) corresponding to the clinal structure of sea scallops.

Given the importance of cold temperatures in both analyses, the results of Bayesian clustering were overlaid on a map with mean winter BT (Fig. 1b) as it was identified in both analyses and is ecologically relevant to this benthic species. The relationship between admixture coefficient $(\mathrm{Q}$ value) and winter $\mathrm{BT}$ was also modeled using a generalized linear model (Fig. 5; $p<0.01$ ).

\section{Discussion}

Understanding connectivity in the ocean is essential to fishery management and conservation. Recent advances in population genetics and genomics increasingly reveal unexpected fine-scale heterogeneity in marine species despite high dispersal potential (Reiss et al. 2009; Gagnaire et al. 2015). Here, targeted genetic analyses and expanded geographic coverage confirmed previous observations of northern and southern groups of sea scallop within the northwest Atlantic Ocean (Van Wyngaarden et al. 2017; 2018) but also revealed novel fine-scale structure between 

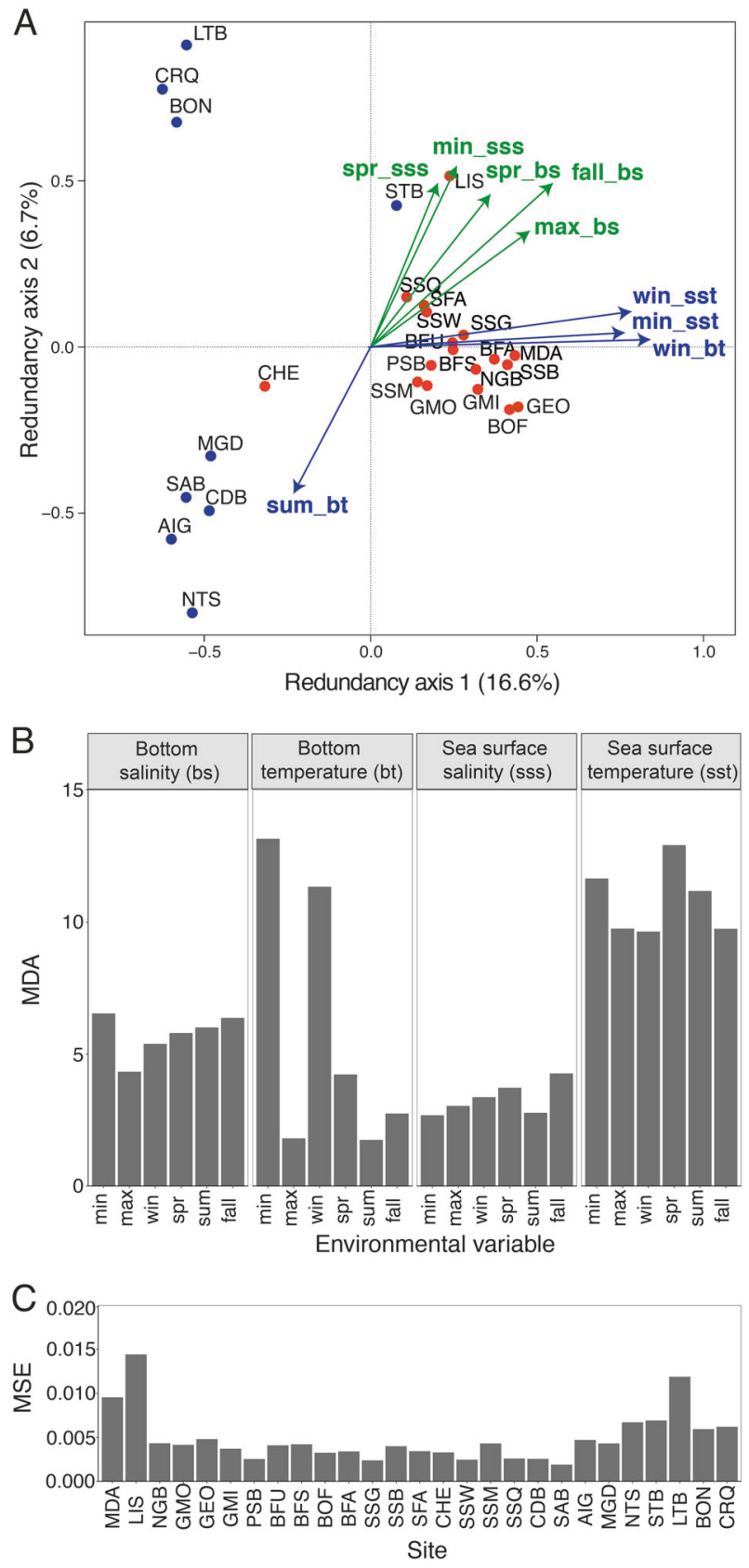

Fig. 4 Results of genetic-environment associations for sea scallop (Placopecten magellanicus) using population allele frequencies including (a) redundancy analysis and $(\mathbf{b}, \mathbf{c})$ random forest regression. a Redundancy analysis shows all selected environmental variables with arrow colors corresponding to salinity (green) and temperature (blue) measures, and site data point are colored based on their location being north (blue) or south (red) of the previously described genetic breakpoint. For random forest regressions, (b) the mean decrease in accuracy (MDA) for each environmental variable and (c) site-specific mean squared error (MSE) were averaged across all runs and loci

inshore and offshore sea scallop populations. Observations of climate-associated spatial structuring observed between inshore and offshore locations extend previous reports of large-scale latitudinal structure, and add further support to

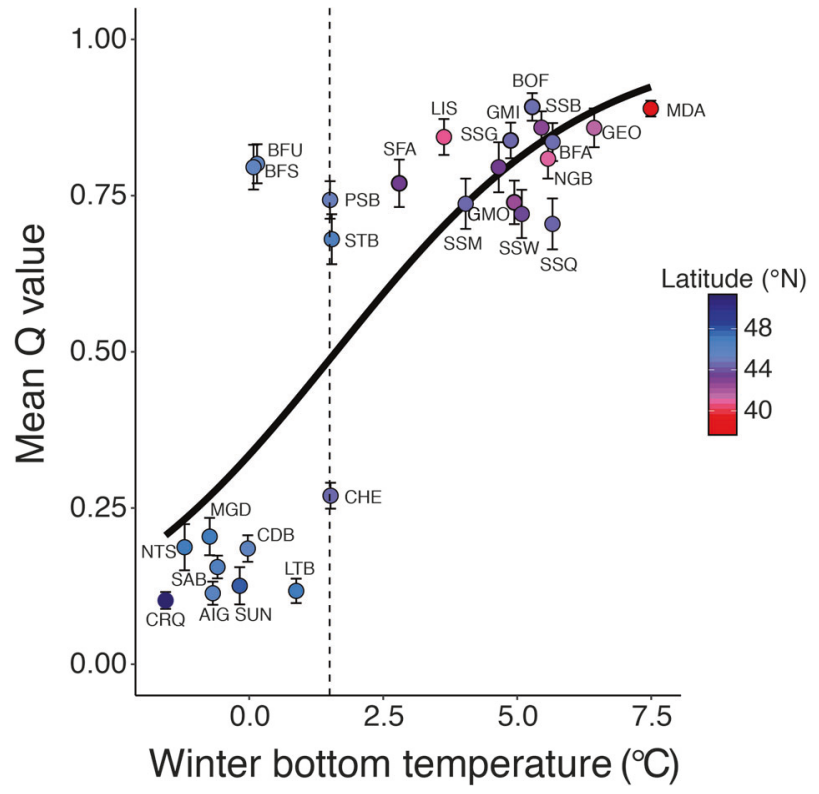

Fig. 5 Relationship between genetic structure (admixture coefficient; $Q$ value with standard error) and average winter bottom temperature across sea scallop (Placopecten magellanicus) populations modeled as a generalized linear model. Site names are indicated near each data point and colored based on latitude. Vertical dashed line represents a possible thermal threshold $\left(1.5^{\circ} \mathrm{C}\right)$ delineating the majority of the sites between the southern and northern genetic clusters (see Discussion)

the hypothesis that gene flow in this species is associated with marine climate. Our work adds to the growing evidence of fine-scale genetic structure in marine species and provides valuable information for management of the economically significant sea scallop.

\section{Fine-scale genetic structure}

In our study we identified novel fine-scale genetic structure between inshore and offshore scallop populations. Previous work has clearly identified discrete northern and southern clusters of sea scallop populations with a boundary off eastern NS (Van Wyngaarden et al. 2017). Interestingly, we observed samples in both the northern and southern regions that unexpectedly clustered with the non-local group. In the northern region, scallops from the offshore site St. Pierre Bank unexpectedly grouped with the southern genetic cluster, and contrasted nearby ( $\geq 181 \mathrm{~km}$ distance) inshore sites in NL that grouped with the northern genetic cluster. This was unexpected, given St. Pierre Bank's northern location $\left(\sim 46.5^{\circ} \mathrm{N}\right)$ and because a previous microsatellitebased study did not identify differences between St. Pierre Bank and another NL site (Kenchington et al. 2006). Furthermore, ocean currents in this region would be expected to facilitate larval connectivity between St. Pierre Bank and nearby northern locations (Naidu and Anderson 1984; Townsend et al. 2004). It has been suggested that STB is a 
highly variable stock with sporadic recruitment (Naidu and Anderson 1984) potentially explaining differences between our study and previous work in which STB scallops were sampled multiple decades earlier (Kenchington et al. 2006). Therefore, we acknowledge the possibility that the southern signature detected at STB may reflect stochastic effects that can only be resolved with additional temporal genetic sampling; nonetheless, our results for STB are consistent with the hypothesis of temperature-mediated genetic structure (discussed below).

In the southern region, again unexpected fine-scale structure was observed between inshore and offshore locations, with the clustering of inshore NS sites, specifically Chester $\left(\sim 44.5^{\circ} \mathrm{N}\right)$ and Chedabucto $\left(\sim 45.5^{\circ} \mathrm{N}\right)$, with the northern genetic group. This again contrasted nearby ( $\geq 128 \mathrm{~km}$ distance) offshore sites at similar latitudes $\left(\sim 44-44.5^{\circ} \mathrm{N}\right)$ on the eastern Scotian Shelf, which clustered with the southern group. In both instances (i.e., north and south), observations of unexpected differentiation between these offshore and inshore sites occur over distances that are within or below the predicted or estimated effective dispersal distances of sea scallop (Van Wyngaarden et al. 2017), suggesting that mechanisms other than passive larval dispersal alone are likely contributing to this previously uncharacterized fine-scale genetic structure.

No previous genetic studies have characterized the differences between inshore and offshore sea scallops found here, although complex patterns of genetic differentiation within offshore or within inshore sea scallop populations have been previously documented (Kenchington et al. 2006; Owen and Rawson, 2013). For example, significant genetic differentiation was found between closely spaced $(\sim 90 \mathrm{~km})$ inshore locations in the Gulf of Maine, potentially resulting from sweepstakes recruitment or oceanographic features (Owen and Rawson 2013). In addition, fine-scale genetic differences were found by Kenchington et al. 2006 between scallops at adjacent $(300 \mathrm{~km})$ offshore sites on Georges Bank, although no specific mechanism could explain this isolation. Unlike Kenchington et al. 2006, we found no differences between adjacent $(240 \mathrm{~km})$ offshore sites on Georges Bank (GEO and NGB sites in our study). Our findings are consistent with other studies that did not find limited connectivity (Tremblay et al. 1994; Gilbert et al. 2010; Davies et al. 2014) or genetic structure (Van Wyngaarden et al. 2017) on Georges Bank. We acknowledge that some genetic structure present within local regions (i.e., within the southern and within the northern genetic clusters) identified using neutral markers (Kenchington et al. 2006; Owen and Rawson 2013) may not be as easily identified using our diagnostic SNPs, which were chosen to discriminate between southern and northern clusters. Even so, we still detected strong genetic differentiation (i.e., north vs. south clustering and high $F_{\mathrm{ST}}$ ) at small geographic scales within regions. Altogether, our results support the hypothesis that significant population structure exists in sea scallop in the northwest Atlantic Ocean and that mechanisms other than larval dispersal alone likely underpin this structure.

\section{Factors contributing to genetic structure}

Admittedly, fine-scale structure can be driven by natural selection, where adaptation to the local environment can facilitate genetic divergence over small spatial scales (Clarke et al. 2010; Bradbury et al. 2013; Milano et al. 2014; Silva et al. 2014). Previous studies in sea scallops have identified biological differences across depths including variation in growth rate and reproductive output likely related to variation in food availability and temperature (Barber et al. 1988; MacDonald and Thompson 1988). Indeed, cold temperatures have been suggested as a potential driver of genetic variation (Van Wyngaarden et al. 2018). In our study, both redundancy analyses and random forest regressions support the role of cold temperatures in mediating genetic structure in sea scallop (see Fig. 1b). Interestingly, salinity variables were also identified in the redundancy analyses, particularly for differentiating sites in the Gulf of St. Lawrence and inshore NS from sites in other geographic regions; however, variation in salinity across the latitudinal range does not differentiate southern and northern genetic structure.

Our results strengthen the conclusions drawn by Van Wyngaarden et al. 2018, suggesting that the coldest temperatures (winter and annual minima) experienced by scallops drive differences between northern and southern clusters, consistent with temperature-mediated genetic structure of several other species in the North Atlantic (Bradbury et al. 2010; Jorde et al. 2015; Benestan et al. 2016; Jeffery et al. 2018). Differences in thermal tolerance have been detected between scallops collected from locations within the southern (Passamaquoddy Bay; PSB) and northern (Gulf of St. Lawrence) genetic clusters of our study (Dickie 1958). Here we suggest that cold temperatures may also facilitate fine-scale genetic differences between the inshore and offshore scallops, where an important thermal threshold may exist near $1.5^{\circ} \mathrm{C}$ based on average winter BT. The majority of stocks assigned to the southern genetic cluster were found at locations where winter BT exceeded $1.5^{\circ} \mathrm{C}$ (exceptions being two inner Bay of Fundy sites: BFU and BFS), and all stocks assigned to the northern genetic cluster were found at locations with average winter BTs below $1.5^{\circ} \mathrm{C}$ (see Fig. 5).

Interestingly, our attempts to explore the temporal stability of these patterns across the early-life history suggest no significant changes in the proportion of north and south juvenile scallop (spat) collected pre- and post winter. This may be somewhat inconsistent with a hypothesis of high 
dispersal and strong selection driving the patterns observed. However, we acknowledge that the site locations, sampling year, and genetic markers used in our study may complicate the interpretation of these results. For example, for a change in the proportion of groups present in a sample to be detected, a site would need recruits from both northern and southern clusters, and this may be unlikely for many of these sampling sites. In addition, temporal genetic differences (i.e., between adults and juveniles collected in different years) were found at one site in our study (PSB), and thus, given the complex population dynamics of scallops, further examination, and additional temporal comparisons across multiple spatial scales may be warranted. Future experimental studies are needed to determine whether cold tolerance drives adaptive differences between scallop populations.

\section{Management implications}

Sea scallops represent an economically significant fishery in Canada and the US (NOAA, 2016; DFO, 2016a), and many of our sampling sites represent different management areas in North America (DFO, 2014a, 2014b, 2015; NOAA, 2017). Although we show fine-scale genetic differences between sites at higher latitudes, the current management areas correspond well to the genetic structure in our study, and inshore and offshore sites are managed separately (DFO, 2014a, 2015, 2016b). However, given the observed importance of temperature to the genetic structure of sea scallop and other marine organisms in the northwest Atlantic Ocean, the potential influence of climate change on species distribution may vary intraspecifically among southern and northern groups as predicted for several invertebrate and fish species (Le Bris et al. 2018; Stanley et al. 2018). Specifically, in sea scallops, forecasting models predict a greater increase in the spatial extent of suitable habitat for the northern genetic cluster relative to the southern group (Stanley et al. 2018). Therefore, clear resolution of the current spatial genetic structure and environmental associations can facilitate improved understanding and predictions of population responses to climate change.

\section{Summary}

In our study, we identified significant global and local genetic structure in sea scallops over the largest geographic range to date. The delineation between northern and southern genetic clusters of sea scallop was consistent with previous observations of sea scallop (Kenchington et al. 2006; Van Wyngaarden et al. 2017), as well as northern shrimp (Pandalus borealis; Jorde et al. 2015), green crab (Carcinus maenas; Jeffery et al. 2017), Atlantic cod (Bradbury et al. 2010), and American lobster (Homarus americanus; Benestan et al. 2016) in the northwest Atlantic Ocean (see Stanley et al. 2018). However, our results show that the boundary between northern and southern groups is not a discrete latitudinal break (Van Wyngaarden et al. 2017), as we show that variation in cold temperature around this boundary mediates population structure and aligns with fine-scale differences between inshore and offshore scallops. In conclusion, our results provide valuable fine-scale information for the management of sea scallop populations, highlighting the potential value of using environmental data to predict genetic structure, which can help create management actions that match biological units.

\section{Data Archiving}

Genotype data for 96 SNPs and environmental data are available from the Dryad Digital Repository https://doi.org/ $10.5061 /$ dryad.59g2911

Acknowledgements We thank the people and organizations who contributed scallop samples, including NOAA (Devora Hart, Jakub Kircun), Maine Department of Marine Resources (Kevin Kelly), Fisheries and Oceans Canada (Amy Glass, Alan Reeves, Kyle Matheson, Leslie-Anne Davidson, Shawn Robinson, Leslie Nasmith, Andrew Cooper, Elizabeth Coughlan, Phil Sargent and Carole Turbide) and Sam Truesdale. We also thank the staff of the Aquatic Biotechnology Lab at the Bedford Institute of Oceanography for assistance with DNA extractions, RAD library preparation and SNP genotyping, and Praveen Nadukkalam Ravindran for bioinformatic support. This work was supported by a National Sciences and Engineering Research Council of Canada (NSERC) visiting fellowship awarded to S.J.L.

\section{Compliance with ethical standards}

Conflict of interest The authors declare that they have no conflict of interest.

\section{References}

Barber BJ, Getchell R, Shumway S, Schick D (1988) Reduced fecundity in a deep-water population of the giant scallop Placopecten magellanicus in the Gulf of Maine, USA. Mar Ecol Prog Ser 42:207-12

Benestan L, Gosselin T, Perrier C, Sainte-Marie B, Rochette R, Bernatchez L (2015) RAD genotyping reveals fine-scale genetic structuring and provides powerful population assignment in a widely distributed marine species, the American lobster (Homarus americanus). Mol Ecol 24:3299-315

Benestan L, Quinn BK, Maaroufi H, Laporte M, Clark FK, Greenwood SJ et al. (2016) Seascape genomics provides evidence for thermal adaptation and current-mediated population structure in American lobster (Homarus americanus). Mol Ecol 25:5073-92

Besnier F, Glover KA (2013) ParallelStructure: a R package to distribute parallel runs of the population genetics program STRUCTURE on multi-core computers. PLoS ONE 8:e70651

Bradbury IR, Campana SE, Bentzen P (2008) Low genetic connectivity in an estuarine fish with pelagic larvae. Can J Fish Aquat Sci 65:147-58 
Bradbury IR, Hubert S, Higgins B, Borza T, Bowman S, Paterson IG et al. (2010) Parallel adaptive evolution of Atlantic cod on both sides of the Atlantic Ocean in response to temperature. Proc $\mathrm{R}$ Soc Lond B 277:3725-34

Bradbury IR, Hubert S, Higgins B, Bowman S, Borza T, Paterson IG et al. (2013) Genomic islands of divergence and their consequences for the resolution of spatial structure in an exploited marine fish. Evol Appl 6:450-61

Breiman L (2001) Random forests. Mach Learn 45:5-32

Brickman D, Wang Z, DeTracey D (2016) High resolution future climate ocean model simulations for the northwest Atlantic shelf region. Can Tech Rep Hydrogr Ocean Sci 315:1-143

Cavalli-Sforza LL, Edwards AWF (1967) Phylogenetic analysis models and estimation procedures. Am J Hum Genet 19:233-57

Clarke LM, Munch SB, Thorrold SR, Conover DO (2010) High connectivity among locally adapted populations of a marine fish (Menidia menidia). Ecology 91:3526-37

Cowen RK, Sponaugle S (2009) Larval dispersal and marine population connectivity. Ann Rev Mar Sci 1:443-66

Culliney JL (1974) Larval development of the giant scallop Placopecten magellanicus (Gmelin). Biol Bull 147:321-32

Davies KTA, Gentleman WC, DiBacco C, Johnson CL (2014) Semiannual spawning in marine scallops strengthens larval recruitment and connectivity on Georges Bank: a model study. Mar Ecol Prog Ser 516:209-27

DFO (2014a). Eastern Canada sea scallop (offshore). http://www.dfompo.gc.ca/fm-gp/sustainable-durable/fisheries-peches/scalloppetoncle-eng.htm.

DFO (2014b). Scallop fishing area. http://www.glf.dfo-mpo.gc.ca/ Gulf/Fishing-Area-Maps/Scallop.

DFO (2015). Inshore scallop - maritimes region. http://www.dfo-mpo. gc.ca/fm-gp/peches-fisheries/ifmp-gmp/scallop-petoncle/scalloppetoncle2015-sec1-eng.htm.

DFO (2016a). Commercial fisheries: landings. http://www.dfo-mpo. gc.ca/stats/commercial/land-debarq/sea-maritimes/s2015av-eng. htm.

DFO (2016b). An assessment of sea scallop on the St. Pierre Bank (Subdivision 3Ps). DFO Canadian Science Advisory Secretariat Science Advisory Report. 2016/032

Dickie LM (1958) Effects of high temperature on survival of the giant scallop. J Fish Res Board Can 15:1189-211

Duffy TA, Hice LA, Conover DO (2015) Pattern and scale of geographic variation in environmental sex determination in the Atlantic silverside Menidia Menidia. Evol 69:2187-95

Earl DA, vonHoldt BM (2012) STRUCTURE HARVESTER: a website and program for visualizing STRUCTURE output and implementing the Evanno method. Conserv Genet Res 4:359-61

Evanno G, Regnaut S, Goudet J (2005) Detecting the number of clusters of individuals using the software STRUCTURE: a simulation study. Mol Ecol 14:2611-20

Excoffier L, Lischer HE (2010) Arlequin suite ver 3.5: a new series of programs to perform population genetics analyses under Linux and Windows. Mol Ecol Res 10:564-7

Gagnaire PA, Broquet T, Aurelle D, Viard F, Souissi A, Bonhomme F et al. (2015) Using neutral, selected, and hitchhiker loci to assess connectivity of marine populations in the genomic era. Evol Appl 8:769-86

Gaither MR, Jones SA, Kelley C, Newman SJ, Sorenson L, Bowen BW (2011) High connectivity in the deepwater snapper Pristipomoides filamentosus (Lutjanidae) across the Indo-Pacific with isolation of the Hawaiian archipelago. PLoS ONE 6:e28913

Gilbert CS, Gentleman WC, Johnson CL, DiBacco C, Pringle JM, Chen C (2010) Modelling dispersal of sea scallop (Placopecten magellanicus) larvae on Georges Bank: the influence of depthdistribution, planktonic duration and spawning seasonality. Prog Oceanogr 87:37-48
Hauser L, Carvalho GR (2008) Paradigm shifts in marine fisheries genetics ugly hypotheses slain by beautiful facts. Fish Fish 9:333-62

Hellberg ME (2009) Gene flow and isolation among populations of marine animals. Ann Rev Ecol Evol Syst 40:291-310

Hess JE, Campbell NR, Docker MF, Baker C, Jackson A, Lampman $\mathrm{R}$ et al. (2015) Use of genotyping by sequencing data to develop a high-throughput and multifunctional SNP panel for conservation applications in Pacific lamprey. Mol Ecol Res $15: 187-202$

Jeffery NW, Bradbury IR, Stanley RRE, Wringe BF, Van Wyngaarden M, Lowen B et al. (2018). Genome wide evidence of environmentally mediated invasion success in European green crab (Carcinus maenas) in eastern North America. Evol Appl, https:// doi.org/10.1111/eva.12601.

Jeffery NW, DiBacco C, Van Wyngaarden M, Hamilton LC, Stanley RRE, Bernier R et al. (2017) RAD sequencing reveals genomewide divergence between independent invasions of the European green crab (Carcinus maenas) in the Northwest Atlantic. Ecol Evol 7:2513-24

Jombart T (2008) adegenet: a R package for the multivariate analysis of genetic markers. Bioinformatics 24:1403-5

Jombart T, Devillard S, Dufour AB, Pontier D (2008) Revealing cryptic spatial patterns in genetic variability by a new multivariate method. Heredity 101:92-103

Jones GP, Planes S, Thorrold SR (2005) Coral reef fish larvae settle close to home. Curr Biol 15:1314-8

Jorde PE, Sovik G, Westgaard JI, Albretsen J, André C, Hvingel C et al. (2015) Genetically distinct populations of northern shrimp, Pandalus borealis, in the North Atlantic: adaptation to different temperatures as an isolation factor. Mol Ecol 24:1742-57

Jørgensen HB, Hansen MM, Bekkevold D, Ruzzante DE, Loeschcke V (2005) Marine landscapes and population genetic structure of herring (Clupea harengus L.) in the Baltic Sea. Mol Ecol 14:3219-34

Kenchington EL, Patwary MU, Zouros E, Bird CJ (2006) Genetic differentiation in relation to marine landscape in a broadcastspawning bivalve mollusc (Placopecten magellanicus). Mol Ecol 15:1781-96

Knutsen H, Olsen EM, Ciannelli L, Espeland SH, Knutsen JA, Simonsen JH et al. (2007) Egg distribution, bottom topography and small-scale population structure in a coastal marine system. Mar Ecol Prog Ser 333:249-55

Kopelman NM, Mayzel J, Jakobsson M, Rosenberg NA, Mayrose I (2015) Clumpak: a program for identifying clustering modes and packaging population structure inferences across K. Mol Ecol Res 15:1179-91

Langella O (2012). POPULATIONS 1.2.28. Population genetic software (individuals or populations distances, phylogenetic trees). https://launchpad.net/ olivier-langella/+archive/ubuntu/ppa.

Larson WA, Utter FM, Myers KW, Templin WD, Seeb JE, Guthrie Iii CM et al. (2013) Single-nucleotide polymorphisms reveal distribution and migration of Chinook salmon (Oncorhynchus tshawytscha) in the Bering Sea and North Pacific Ocean. Can J Fish Aquat Sci 70:128-41

Le Bris A, Mills KE, Wahle RA, Chen Y, Alexander MA, Allyn AJ et al. (2018) Climate vulnerability and resilience in the most valuable North American fishery. Proc Nat Acad Sci USA 115:1831-1836.

Liaw A, Wiener M (2002) Classification and regression by randomForest. R News 2:18-22

MacDonald BA, Thompson RJ (1988) Intraspecific variation in growth and reproduction in latitudinally differentiated populations of the giant scallop Placopecten magellanicus (Gmelin). Biol Bull 175:361-71 
Melvin GD, Dadswell MJ, Chandler RA (1985). Movement of scallops, Placopecten magellanicus (Gmelin, 1791) (Mollusca: Pectinidae) on Georges Bank. Canadian Atlantic Fisheries Scientific Advisory Committee. Vol. 85/30, p. 29.

Milano I, Babbucci M, Cariani A, Atanassova M, Bekkevold D, Carvalho GR et al. (2014) Outlier SNP markers reveal fine-scale genetic structuring across European hake populations (Merluccius merluccius). Mol Ecol 23:118-35

Momigliano P, Harcourt R, Robbins WD, Jaiteh V, Mahardika GN, Sembiring A et al. (2017) Genetic structure and signatures of selection in grey reef sharks (Carcharhinus amblyrhynchos). Heredity 119:142-53

Naidu KS, Anderson JT (1984). Aspect of scallop recruitment on St. Pierre Bank in relation to oceanography and implications for resource management. Canadian Atlantic Fisheries Science Advisory Committee. 84/29

Naidu KS, Robert G (2006) Fisheries Sea Scallop, Placopecten magellanicus. In: Shumway SE, Parsons GJ (eds) Scallops: biology, ecology and aquaculture. Elsevier, Amsterdam, Netherlands, pp 869-905

NOAA (2016). National marine fisheries service: annual landings by group. https://www.st.nmfs.noaa.gov/commercial-fisheries/ commercial-landings/annual-landings/index.

NOAA (2017). Atlantic sea scallop managed waters. https://www.grea teratlantic.fisheries.noaa.gov/sustainable/species/scallop/.

Oksanen J, Blanchet GF, Friendly M, Kindt R, Legendre P, McGlinn D et al. (2017). vegan: community ecology package (Version 2.43). https://CRAN.R-project.org/package= vegan.

Owen EF, Rawson PD (2013) Small-scale spatial and temporal genetic structure of the Atlantic sea scallop (Placopecten magellanicus) in the inshore Gulf of Maine revealed using AFLPs. Mar Biol 160:3015-25

Pante E, Simon-Bouhet B (2013) marmap: a package for importing, plotting and analyzing bathymetric and topographic data in R. PLoS ONE 8:e73051

Petrou EL, Seeb JE, Hauser L, Witteveen MJ, Templin WD, Seeb LW (2013) Fine-scale sampling reveals distinct isolation by distance patterns in chum salmon (Oncorhynchus keta) populations occupying a glacially dynamic environment. Conserv Genet 15:229-43

Pompanon F, Bonin A, Bellemain E, Taberlet P (2005) Genotyping errors: causes, consequences and solutions. Nat Rev Genet 6:847-846

Posgay JA (1957) The range of the sea scallop. Nautilus 71:55-57

Pritchard JK, Stephens M, Donnelly P (2000) Inference of population structure using multilocus genotype data. Genetics 155:945-59

Rambaut A (2012). FigTree v1.4. http://tree.bio.ed.ac.uk/software/ figtree/.

Reiss H, Hoarau G, Dickey-Collas M, Wolff WJ (2009) Genetic population structure of marine fish: mismatch between biological and fisheries management units. Fish Fish 10:361-95

Richards-Hrdlicka KL (2014). A genomic approach to finding and understanding how the amphibian chytrid fungus is genetically structured in Northeastern America. PhD thesis, Yale University, New Haven, CT.

Schultz ET, Conover DO (1997) Latitudinal differences in somatic energy storage: adaptive responses to seasonality in an estuarine fish (Atherinidae: Menidia menidia). Oecologia 109:516-29

Schultz ET, Conover DO, Ehtisham A (1998) The dead of winter sizedependent variation and genetic differences in seasonal mortality among Atlantic silverside (Atherinidae: Menidia menidia) from different latitudes. Can J Fish Aquat Sci 55:1149-57
Selkoe KA, Henzler CM, Gaines SD (2008) Seascape genetics and the spatial ecology of marine populations. Fish Fish 9:363-77

Silva G, Lima FP, Martel P, Castilho R (2014) Thermal adaptation and clinal mitochondrial DNA variation of European anchovy. Proc R Soc Lond B 281:20141093

Simpson SD, Harrison HB, Claereboudt MR, Planes S (2014) Longdistance dispersal via ocean currents connects Omani clownfish populations throughout entire species range. PLoS ONE 9: e107610

Stanley R, Snelgrove PV, Deyoung B, Gregory RS (2012) Dispersal patterns, active behaviour, and flow environment during early life history of coastal cold water fishes. PLoS ONE 7:e46266

Stanley RR, Jeffery NW, Wringe BF, DiBacco C, Bradbury IR (2017) genepopedit: a simple and flexible tool for manipulating multilocus molecular data in R. Mol Ecol Res 17:12-18

Stanley RRE, DiBacco C, Lowen B, Beiko RG, Jeffery NW, Van Wyngaarden $\mathrm{M}$ et al. (2018) A climate-associated multispecies cryptic cline in the northwest Atlantic. Sci Adv 4:eaaq0929

Taylor MS, Hellberg ME (2003) Genetic evidence for local retention of pelagic larvae in a Caribbean reef fish. Science 299:107-9

Teske PR, Sandoval-Castillo J, van Sebille E, Waters J, Beheregaray LB (2015) On-shelf larval retention limits population connectivity in a coastal broadcast spawner. Mar Ecol Prog Ser 532:1-12

Tian RC, Chen C, Stokesbury KDE, Rothschild B, Cowles GW, Xu Q et al. (2009) Modeling the connectivity between sea scallop populations in the Middle Atlantic Bight and over Georges Bank. Mar Ecol Prog Ser 380:147-60

Townsend DW, Thomas AC, Mayer LM, Thomas MA (2004). Oceanography on the Northwest Atlantic continental shelf $(1, \mathrm{~W})$. In: Robinson AR, Brink KH (eds) The sea: the global coastal ocean: interdisciplinary regional studies and syntheses. Harvard University Press, Cambridge, MA, Vol. 14, pp 119-68.

Tremblay JM, Loder JW, Werner FE, Naimie EC, Page FH, Sinclair MM (1994) Drift of sea scallop larvae Placopecten magellanicus on Georges Bank - A model study of the roles of mean advection, larval behavior and larval origin. Deep Sea Res Part II 41:7-49

Treml EA, Ford JR, Black KP, Swearer SE (2015) Identifying the key biophysical drivers, connectivity outcomes, and metapopulation consequences of larval dispersal in the sea. Mov Ecol 3:17

Truelove NK, Kough AS, Behringer DC, Paris CB, Box SJ, Preziosi RF et al. (2016) Biophysical connectivity explains population genetic structure in a highly dispersive marine species. Coral Reefs 36:233-44

Upton G, Fingleton B (1985). Spatial data analysis by sample. Vol. 1: Point Pattern and Quantitative Data. Wiley, New York.

Van Wyngaarden M, Snelgrove PV, DiBacco C, Hamilton LC, Rodriguez-Ezpeleta N, Jeffery NW et al. (2017) Identifying patterns of dispersal, connectivity and selection in the sea scallop, Placopecten magellanicus, using RADseq-derived SNPs. Evol Appl 10:102-17

Van Wyngaarden M, Snelgrove PV, DiBacco C, Hamilton LC, Rodriguez-Ezpeleta N, Zhan L et al. (2018) Oceanographic variation influences spatial genomic structure in the sea scallop Placopecten magellanicus. Ecol Evol 8:2824-41

Warnes GR, Bolker B, Bonebakker L, Gentleman R, Liaw WHA, Lumley $\mathrm{T}$ et al. (2016). gplots: various $\mathrm{R}$ programming tools for plotting data (Version 3.0.1). https://cran.r-project.org/web/packa ges/gplots/index.html.

Yahagi T, Watanabe HK, Kojima S, Kano Y (2017) Do larvae from deep-sea hydrothermal vents disperse in surface waters? Ecology 98:1524-34 